\title{
Amplified antimicrobial action of chlorhexidine encapsulated in PDAC-functionalized acrylate copolymer nanogel carriers
}

Received 00th January 20xx, Accepted 00th January 20xx

DOI: $10.1039 / \times 0 \times x 00000 x$

www.rsc.org/MCF

\author{
Mohammed J. Al-Awady, ${ }^{\text {a,b }}$ Paul J. Weldrick, ${ }^{a, c}$ Matthew J. Hardman, ${ }^{\mathrm{c}}$ Gillian M. Greenway, ${ }^{\mathrm{a}}$ and \\ Vesselin N. Paunov ${ }^{a *}$
}

\begin{abstract}
We have developed and tested a novel functionalised nanocarrier for chlorhexidine (CHX) which provides a very strong enhancement of its antimicrobial action. The nanocarrier was based on lightly-cross-linked acrylate copolymer nanogel particles loaded with $\mathrm{CHX}$ followed by a surface functionalisation with the cationic polyelectrolyte poly(diallyldimethylammonium chloride (PDAC). We explored the antimicrobial effect of the PDAC-coated CHX-loaded nanogel carriers on E. coli, S. auresus, C. cerevisiae and C. reinhardtii and discovered that it is much higher than that of solution with equivalent overall concentration of free $\mathrm{CHX}$. Our experiments also showed a marked increase of the cationic $\mathrm{CHX}$-loaded nanocarriers antimicrobial action on these microorganisms at shorter incubation times compared with the noncoated $\mathrm{CHX}$-loaded nanogel particles at the same $\mathrm{CHX}$ concentration and other conditions. We attribute the increase in the antimicrobial activity of the cationically-functionalised nanogel carrier to its electrostatic adhesion to the microbial cells walls which allows much higher $\mathrm{CHX}$ concentration to be delivered directly onto the cell surface. The results of this study can be used for development of novel more efficient antialgal, antifungal and antbacterial formulations based on cationically functionalised nanogels. Our method can also be used for boosting the effect of other cationic antimicrobial agents by encapsulating them in cationically-functionalised nanogel carriers. This nanotechnological approach could lead to developing more effective antimicrobial and disinfecting agents, dental formulations for plaque control, wound dressings, antialgal/antibiofouling formulations and novel antifungal agents.
\end{abstract}

\section{Introduction}

Nanocarrier-based drug delivery is a rapidly evolving area aimed at releasing and maintaining optimal concentrations of nanoparticle-encapsulated therapeutic agents to the specifically target infected tissues, tumours, etc. while reducing their side effects on normal tissues. ${ }^{1,2}$ Commonly used nanocarriers for drug delivery include liposomes, polymeric micelles and dendrimers, artificial DNA structures, and biodegradable scaffolds. ${ }^{2}$ Nanogels are internally cross-linked particles of hydrophilic polymer which may contain sulphate, hydroxyl and carboxyl ionisable groups in polymer chains. ${ }^{3}$ Such physically or chemically cross-linking polymer networks can swell in a aqueous suspension due to water absorption. ${ }^{4-5}$ Nanogels have good biocompatibility which is crucial for avoiding inflammatory responses and other side effects. ${ }^{6-8}$ Chlorhexidine gluconate ( $\mathrm{CHX})$ is a cationic bisbiguanide and consists of two symmetric 4-chlorophenyl rings and two

\footnotetext{
a. School of Mathematics and Physical Sciences (Chemistry), University of Hull, Hull, HU67RX, UK

b. Department of Chemistry, Physiology, and Pharmacology, Faculty of Veterinary

Medicine, The Green University of Qasim, Babylon, Iraq.

c. School of Life Sciences, University of Hull, Hull, HU67RX, UK.

*Corresponding author: Tel: +44 1482 465660; Fax: +44 1482 466410; E-mail: v.n.paunov@hull.ac.uk
}

biguanide groups linked by a central hexamethylene chain. $\mathrm{CHX}$ digluconate salt is easily soluble in water ${ }^{9,10}$ and is frequently used as a chemotherapeutic agent especially against oral diseases due to its wide spectrum of activity against yeasts, Gram-positive, Gram-negative bacteria and many anaerobic pathogens. ${ }^{11}$ The $\mathrm{CHX}$ cation binds to anionic groups on the bacterial surface such as phosphate groups of teichoic acid in Gram-positive and lipopolysaccharide in Gram-negative bacteria and disrupts their membrane integrity. ${ }^{12}$ This leads to leakage of the cell constituents and eventually to the cells death. ${ }^{13} \mathrm{CHX}$ is one of the most effective antimicrobial agents for dental plaque control. ${ }^{14-16} \mathrm{~A}$ recent and practical release system is the combination of microfibrillated cellulose (MFC) and $\beta$-cyclodextrin $(\beta-C D)$ that produces a large dosage of chlorhexidine gluconate over a prolonged period of time, MFC is known for its burst action whilst $\beta-C D$ is a slow releasing drug delivery agent. ${ }^{17}$ Mesoporous silica nanoparticles have been recently used as a $\mathrm{CHX}$ release system that effectively targets planktonic and biofilm modes of oral pathogens. ${ }^{18}$ Silica submicrometer size capsules impregnated with $2 \% \mathrm{CHX}$ and coated with sodium alginate and chitosan have been reported as a better root canal drug against Enterococcus faecalis which is a major cause of root canal infections. ${ }^{19}$ Antimicrobial strategies combining polymer science and nanotechnology have attracted tremendous interest in the last decade because of their great potential in many applications. ${ }^{39,40}$ 


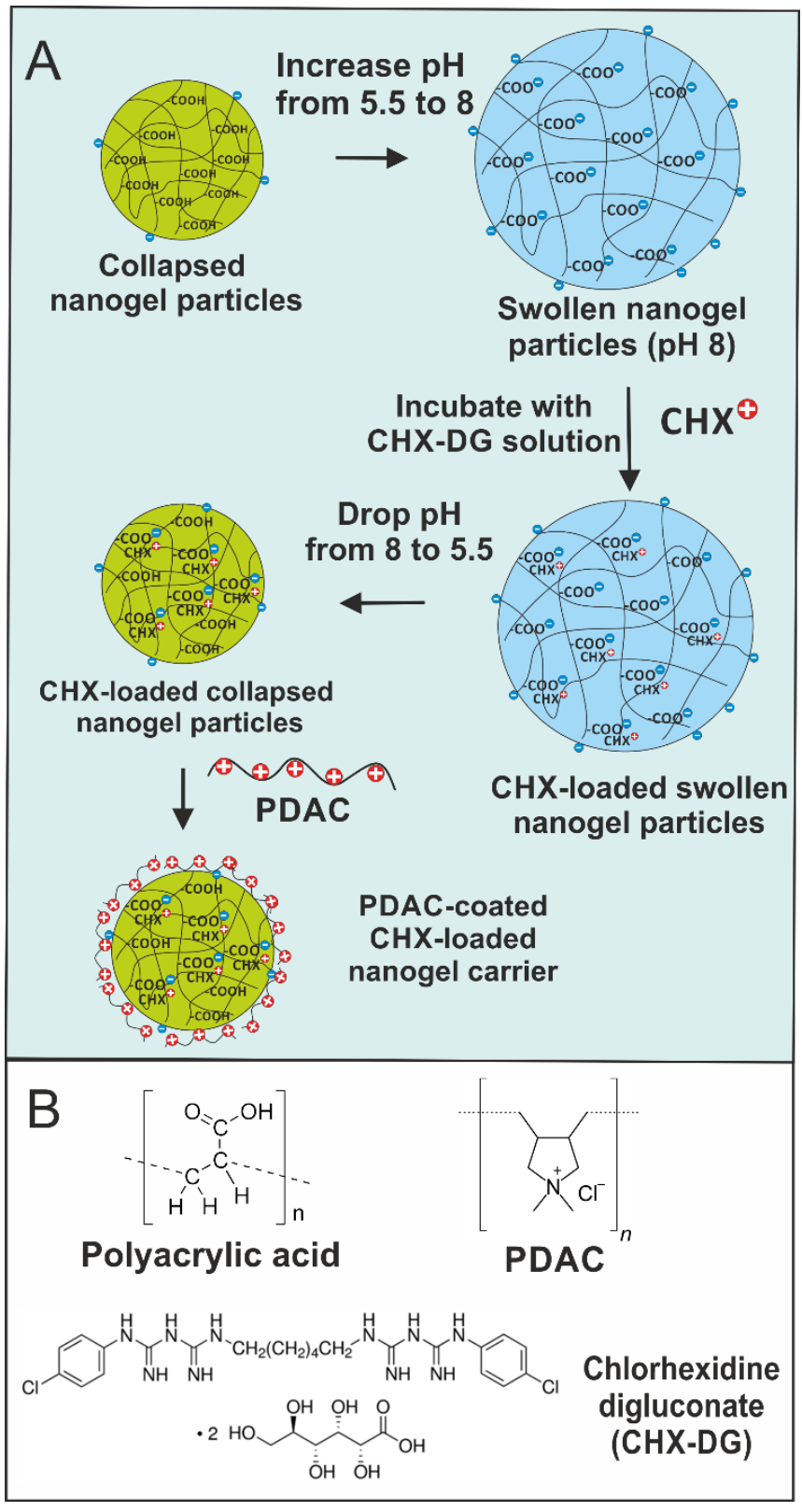

Figure 1. The schematic diagram for the encapsulation of chlorhexidine ( $\mathrm{CHX}$ ) ions from chlorhexidine digluconate) into a Carbopol nanogels by using swelling/deswelling cycle of the nanogel in the basic $(\mathrm{pH} 8)$ and acidic $(\mathrm{pH} 5.5)$ medium, respectively. The $\mathrm{CHX}-$ loaded nanogel was surface-functionalised with a cationic polyelectrolyte (PDAC). The chemical formulas of the carbomer nanogel (partially crosslinked polyacrylic acid NPs), the PDAC and the chlorhexidine digluconate are also presented.

Poly (dl-lactic-co-glycolic acid) (PLGA) microparticles containing chlorhexidine $(\mathrm{CHX})$ free base, chlorhexidine digluconate ( $\mathrm{CHX}$ DG) with methylated- $\beta$-cyclodextrin (MBCD) and hydroxypropyl- $\beta$-cyclodextrin (HPBCD) have recently been explored against periodontitis causing bacteria $(P$. gingivalis and B. forsythus). ${ }^{20}$

Wound treatment needs molecules that both improve healing and control infection. Poly (lactic-co-glycolic acid) (PLGA) microspheres based drug delivery system for $\mathrm{CHX}$ was recently reported which simultaneously transports platelet-derived growth factor (PDGF)-BB, a hydrophilic protein known to stimulate wound healing, and $\mathrm{CHX}$ for infection treatment. This can improve healing and decrease bacteria levels in an infected wound model. ${ }^{21}$ Positively charged CHX-loaded Poly $\epsilon$ caprolactone) (PCL) nanocapsules, prepared by interfacial polymer deposition /solvent displacement were also reported with good encapsulation efficiency. ${ }^{22}$ The study described a sustained release of $\mathrm{CHX}$ from $\mathrm{PCL}$ nanocapsules by mediating a more direct and prolonged contact between the nanocapsules and bacteria, skin surface, and skin follicles and provided a prolonged ex vivo topical antimicrobial activity against Staphylococcus epidermidis. ${ }^{22}$

Antimicrobial nanoparticles (NPs) of hexametaphosphate salt of chlorhexidine $(\mathrm{CHX})$ have been recently produced by coprecipitation of aqueous solutions of $\mathrm{CHX}$ digluconate and sodium hexametaphosphate. These NPs adhered well on glass, titanium, and an elastomeric wound dressing surfaces and showed a slow release of $\mathrm{CHX}$ over a period of at least 50 days proving effective against methicillin-resistant $S$. aureus (MRSA) and $P$. aeruginosa in both planktonic and biofilm conditions. ${ }^{23}$ Recently, nanocarriers formulated from biodegradable materials attracted a lot of attention following concerns about the post-use fate of the nanocarrier formulations. ${ }^{24,25} \mathrm{Al}$-Awady et al. ${ }^{26}$ demonstrated that the nanotoxicity of polyelectrolytecoated $\mathrm{TiO}_{2} \mathrm{NPs}$ changes with the surface charge with those particles with a cationic outer layer (or bare titania nanoparticles at acidic $\mathrm{pH}$ ) being much more toxic than the ones with an outer layer of anionic polyelectrolyte. A range of other antimicrobial particles have recently been developed which use the same approach for delivery of therapeutic alkaloids. ${ }^{27}$ Frangville et al. ${ }^{28}$ developed biodegradable lignin nanoparticles which showed no measurable toxicity against proxy organisms like yeast and microalgae. Recently, these were utilised for silver ion delivery system based on $\mathrm{Ag}^{+}$-loaded lignin nanoparticles which were further coated with cationic polyelectrolyte. ${ }^{29,30}$ The produced silver ion delivery vehicles proved to more efficient antimicrobial agents for a range of bacteria than equivalent concentrations of silver in metallic silver nanoparticles.

In this study, we push forward these ideas to encapsulate $\mathrm{CHX}$ in nanogel particles based on a partially cross-linked acrylate copolymer for antibacterial, antifungal and anti-algal applications. We explore the stability of the $\mathrm{CHX}$-loaded Carbopol nanogel particles (CLC), the $\mathrm{CHX}$ encapsulation efficiency, the controlled release of encapsulated $\mathrm{CHX}$-cations and the antimicrobial activity of the formed CHX-nanogel complexes before and after surface functionalisation with cationic polyelectrolyte. Carbopol Aqua SF1 is an aqueous dispersion approximately $30 \% \mathrm{w} / \mathrm{v}$ of a lightly cross-linked and highly hydrophilic acrylate nanogel which does not exhibit toxicity against a range of microorganisms and does not trigger inflammatory reactions in animal organs. ${ }^{31}$

Figure 1 explains the encapsulation steps of $\mathrm{CHX}$ into the nanogel and the surface functionalisation of the produced nanoparticles with a cationic polyelectrolyte. The retention of the $\mathrm{CHX}$ in the core of the nanogel is based on electrostatic interaction with non-covalent bonding to ensure further release of the antimicrobial agent upon incubation of the loaded nanogel particles with the tested microorganisms. 

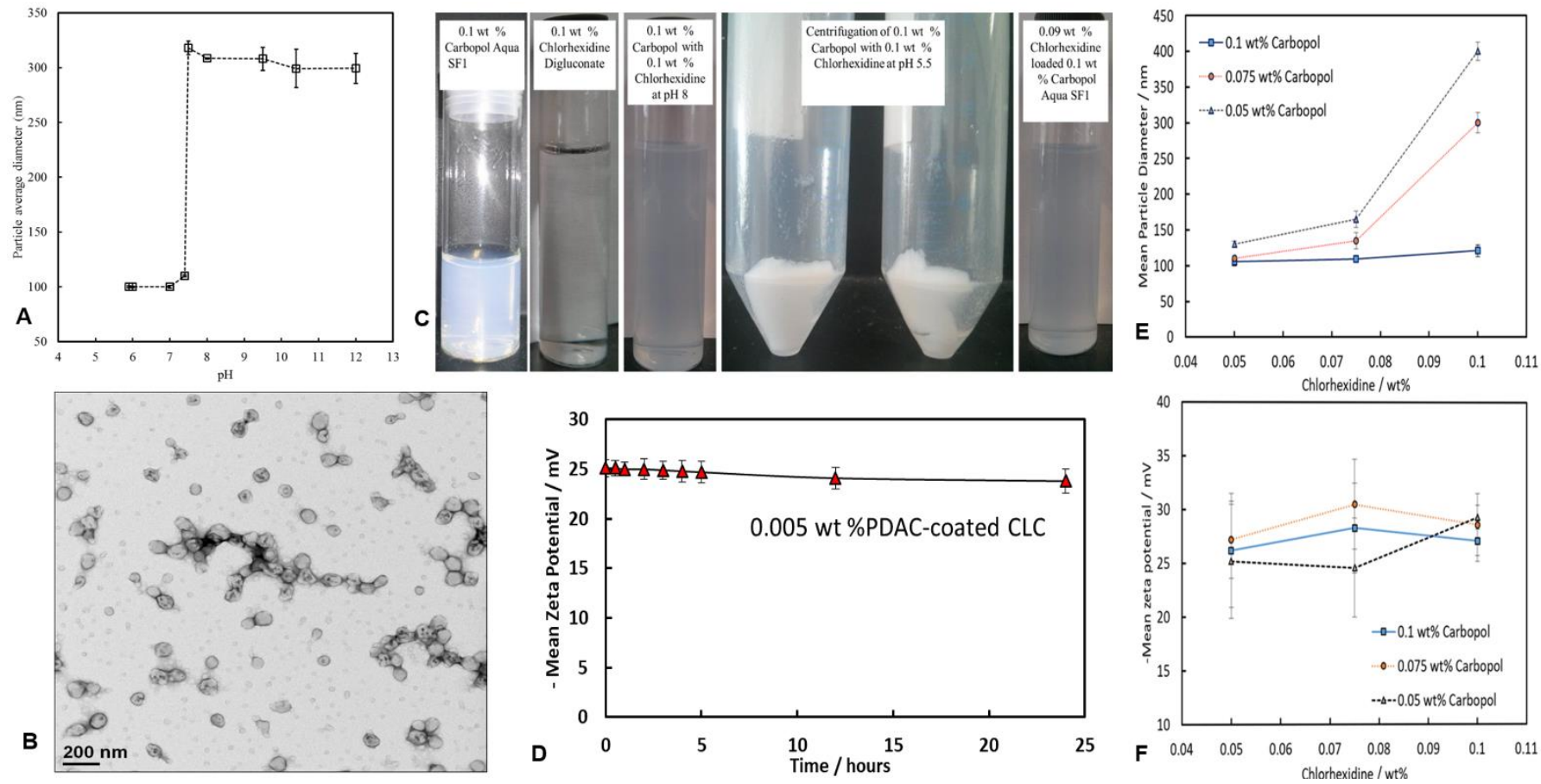

Figure 2. (A) The average particle diameter of Carbopol Aqua SF1 as a function of pH. (B) TEM image of CHX-loaded collapsed Carbopol at pH 5.5 which shows the physical size of the produced collapsed nanogel particles after evaporation of the aqueous media. The encapsulation was achieved through adjusting Carbopol suspension to $\mathrm{pH}$, addition of $\mathrm{CHX}$ solution to form chlorhexidine-loaded swollen Carbopol. The formed suspension was adjusted to pH 5.5 to "collapsed" CHX loaded Carbopol nanogel (CLC). (C) Photograph of bare Carbopol Aqua SF1 suspension, chlorhexidine solution, $\mathrm{CHX}$-loaded Carbopol at pH 8 and pH 5.5 along with a centrifuged CLC particles and the CLC suspension after re-dispersing it at $\mathrm{pH}$ 8. (D) Stability of PDAC-coated Carbopol at pH 5.5. A Malvern Mastersizer was used to measure the zeta potential was measured at time intervals at a refractive index of 1.450. Each value represents a triplicate with \pm SD. (E) The particle hydrodynamic diameter and (F) the mean zeta potential of the CLC particles as a function of the CHX concentration at different concentrations of the Carbopol Aqua SF1.

Here we studied the antibacterial, anti-fungal and antialgal action of CLC on four proxy microorganisms, E. coli, S. aureus, S. cerevisiae and $C$. reinhardtii respectively. We also study the $\mathrm{CHX}$ release kinetics and the boost of its antimicrobial action after coating of the CLC nanocarriers. We show that this strategy can strongly amplify the antimicrobial action of $\mathrm{CHX}$ compared to equivalent concentration of free $\mathrm{CHX}$. This versatile and inexpensive nanocarrier can potentially be used for many other cationic antimicrobial agents and antibiotics to provide a boost of their action or minimize their overall concentration.

\section{Materials and Methods}

\section{Materials}

We used Carbopol Aqua SF1 ${ }^{\mathrm{TM}}$ nanogel as an aqueous suspension (30 wt\%) as supplied by Lubrizol, USA. Fluorescein diacetate (FDA, 98\%) for cell viability assays and poly(diallyldimethylammonium chloride) (PDAC) was supplied from Sigma Aldrich, UK. Chlorhexidine digluconate (98\%) and was delivered by Fluka, UK. Chlamydomonas Reinhardtii (cc-124 strain, was sourced from Flickinger's group at North Carolina State University, USA). It is a microalgae culture which was grown in Tris-Acetate-Phosphate (TAP) culture medium with an incubation temperature of $30{ }^{\circ} \mathrm{C}$. The culture media for $C$. reinhardtii consisted of TAP salts $\left(\mathrm{NH}_{4} \mathrm{Cl} ; \mathrm{MgSO}_{4} .7 \mathrm{H}_{2} \mathrm{O}\right.$ and $\mathrm{CaCl}_{2} \cdot 2 \mathrm{H}_{2} \mathrm{O}$ ), phosphate buffer solution (PBS) and Hunter's trace elements solution (EDTA disodium salt, $\mathrm{ZnSO}_{4} .7 \mathrm{H}_{2} \mathrm{O}, \mathrm{H}_{3} \mathrm{BO}_{3}$, $\mathrm{MnCl}_{2} .4 \mathrm{H}_{2} \mathrm{O}, \quad \mathrm{CoCl}_{2} .6 \mathrm{H}_{2} \mathrm{O}, \mathrm{CuSO}_{4} .5 \mathrm{H}_{2} \mathrm{O}, \mathrm{FeSO}_{4} .7 \mathrm{H}_{2} \mathrm{O}$, $\left(\mathrm{NH}_{4}\right)_{6} \mathrm{Mo}_{7} \mathrm{O}_{24} .4 \mathrm{H}_{2} \mathrm{O}$, all purchased from Sigma-Aldrich, UK. The microalgae batch was grown in the TAP media at $\mathrm{pH} 7$ while being illuminated for 72 hours with a white luminescent lamp with a light intensity of $60 \mathrm{~W} \mathrm{~m}^{-2}$ under constant stirring with a magnetic stirrer. ${ }^{32,33}$ The stock cultures of $C$. reinhardtii which were used for testing were with typical concentration $4 \times 10^{5}$ cells per $\mathrm{mL}$ determined by automatic cell counter (Cellometer Auto $\mathrm{X} 4$ ) and the E. coli bacterial culture stock was with approximately $5 \times 10^{7}$ cells per $\mathrm{mL}$. Deionised water purified by reverse osmosis and ion exchange from a Milli-Q water system (Millipore, UK) was used in all our studies. Its surface tension was $71.9 \mathrm{mNm}^{-1}$ at $25^{\circ} \mathrm{C}$, with measured resistivity of $18 \mathrm{M} \Omega \mathrm{cm}$.

\section{Preparation of CHX-loaded Carbopol nanogel particles (CLC)}

The method is based on a pH induced swelling-deswelling cycle. A 0.1 wt.\% aqueous dispersion of the nanogel was prepared by weighing $0.1 \mathrm{~g}$ of stock solution of the Carbopol Aqua SF1 and dispersing it in $75 \mathrm{~mL}$ Milli-Q water, this was then adjusted to $\mathrm{pH} 8$ using 3 drops of $0.25 \mathrm{M} \mathrm{NaOH}$. An aliquot of 0.1 wt. \% of chlorhexidine digluconate was then added dropwise to the Carbopol Aqua SF1 solution to prepare a $0.1 \mathrm{wt}$ \% chlorhexidine in 0.1 wt. \% nanogel dispersion. CHX-Carbopol solutions was reduced to $\mathrm{pH} 5.5$ using drops of $0.25 \mathrm{M} \mathrm{HCl}$ whilst being stirred for 30 minutes. Solutions was the centrifuged at $8500 \mathrm{rpm}$ for 30 minutes. 


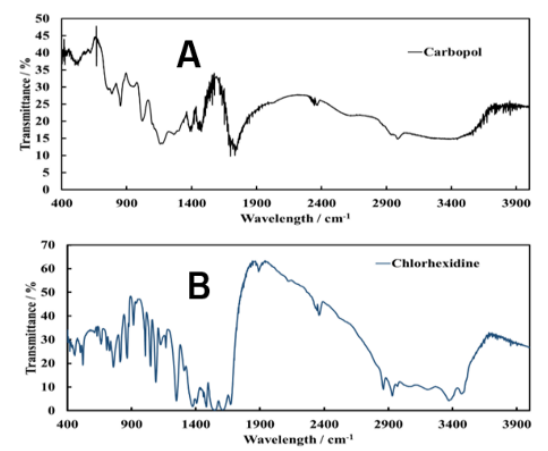

Temperature $/{ }^{\circ} \mathrm{C}$

100150200250300350400450500550600650700750800850900
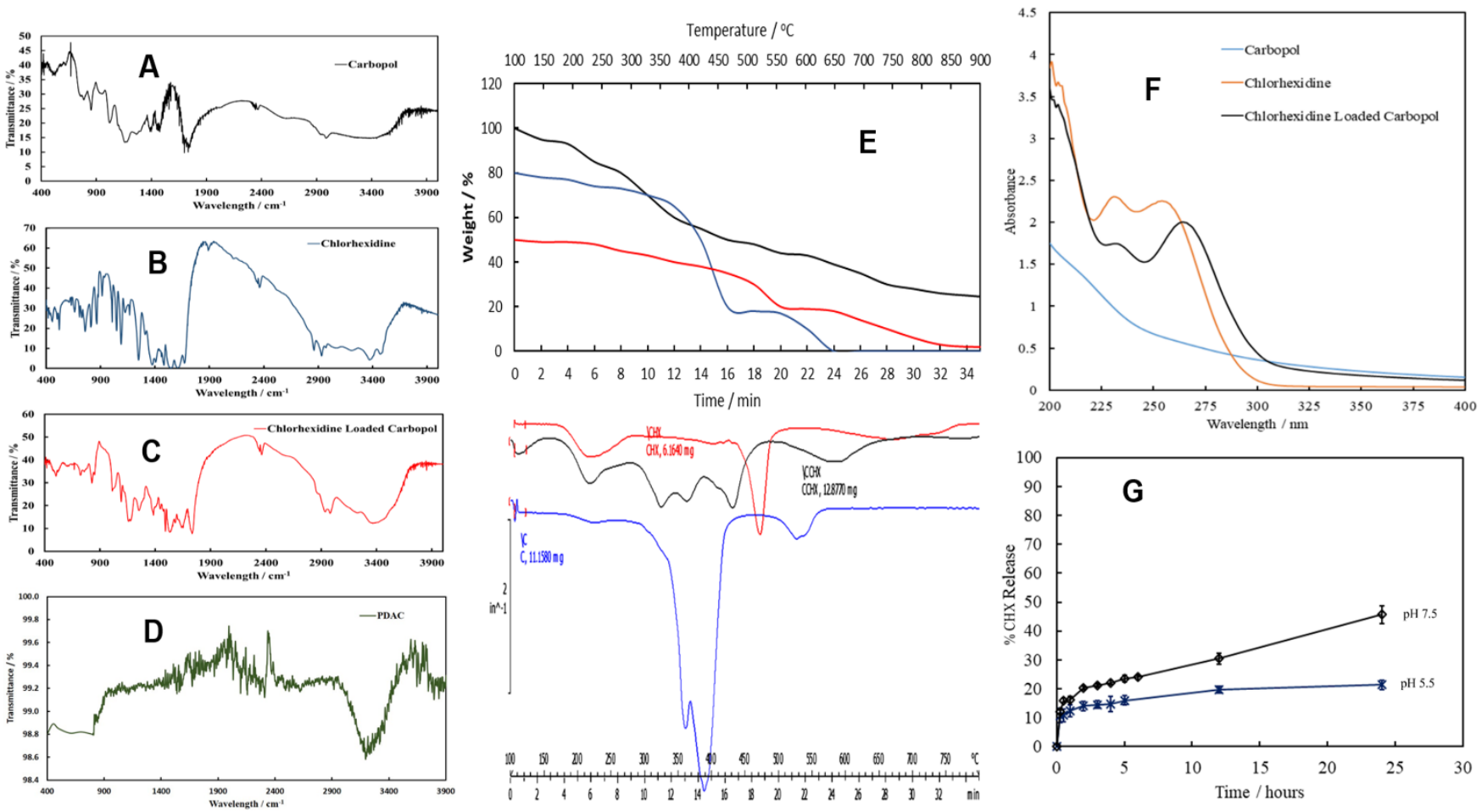

Figure 3. The Fourier Transform-IR spectrum of Carbopol Aqua SF1 (A), chlorhexidine (B), CLC (C) and PDAC (D). These materials were dried and mixed with excess of KBr pellets to prepared $\mathrm{KBr}$ discs for each of Carbopol nanogel, $\mathrm{CHX}$ and CLC which in turn were scanned individually from $400 \mathrm{~cm}^{-1}$ to $4000 \mathrm{~cm}^{-1}$. (E) Thermal Gravimetric Analysis (TGA) and Differential Thermal Analysis (DTA) of chlorhexidine (red line), Carbopol Aqua SF1 (blue line) and CLC (black line) from $100{ }^{\circ} \mathrm{C}$ to $900{ }^{\circ} \mathrm{C}$ at $10^{\circ} \mathrm{C} / \mathrm{min}$ in air atmosphere with purge rate of $10 \mathrm{~mL} \mathrm{~min}^{-1}$. (F) The UV/vis absorbance spectrum of $0.01 \mathrm{wt} \%$ Carbopol Aqua SF1 (Blue line), $0.007 \mathrm{wt} \% \mathrm{CHX}$ (Orange line) and $0.006 \mathrm{wt} \% \mathrm{CLC}$ (Black line). (G) The percentage of $\mathrm{CHX}$ release as a function of time for $0.15 \mathrm{wt} \% \mathrm{CHX}$-loaded in $0.1 \mathrm{wt} \%$ Carbopol (CLC). The experiment was conducted using $10 \mathrm{~K} \mathrm{MWCO}$ dialysis bag filled up with $50 \mathrm{~mL}$ of $\mathrm{CLC}$ suspension. The whole dialysis bag was dipped in a beaker filled with $500 \mathrm{~mL}$ of either acetate buffer solution at pH 5.5 or phosphate buffer at pH 7.5 . The $\mathrm{CHX}$ concentration in the buffer was monitored spectroscopically and calculated from Figure 2D.

The precipitate was washed twice with Milli-Q water and the supernatant discarded. $20 \mathrm{~mL}$ of Milli-Q water was added to the precipitate, the $\mathrm{pH}$ was gradually increased to 8 using drops of $0.25 \mathrm{M} \mathrm{NaOH}$ and the solution stirred overnight. The following morning the $\mathrm{pH}$ of the $\mathrm{CHX}$-Carbopol (CLC) solution was reduced to 5.5 using acetate buffer. We measured the size distribution and zeta-potential of a range of solutions prepared by mixing aqueous solutions of different concentrations of $\mathrm{CHX}$ and the nanogel suspension. A Malvern Mastersizer was used to measure the CLC particle hydrodynamic diameter at a refractive index of 1.450 . The $\mathrm{pH}$ was adjusted with $0.25 \mathrm{M} \mathrm{HCl}$ or $0.25 \mathrm{M}$ $\mathrm{NaOH}$ solutions. Each value represents the average of a triple replicate with \pm S.D.

\section{Release kinetics of CHX from CLC}

We investigated the percentage of in vitro $\mathrm{CHX}$ released using aliquots of equivalent concentrations of $\mathrm{CHX}$-loaded $0.1 \mathrm{wt} \%$ Carbopol nanogel. This formulation was optimized in terms of stability. The particle size and zeta potential of the $\mathrm{CHX}$-loaded nanogel particles at $\mathrm{pH} 5.5$ were $135 \mathrm{~nm}$ and $-30 \mathrm{mV}$, respectively. The $\mathrm{CHX}$-loaded nanogel suspension was placed into a dialysis cassette (10K MWCO, Thermo Fisher, UK) which released the $\mathrm{CHX}$ leaching from the nanogel through the membrane. The dialysis device was placed into a beaker which was already pre-filled with: (i) an acetate buffer solution at $\mathrm{pH}$
5.5 or (ii) a phosphate buffer at pH 7.5 in order to monitor the amount of released $\mathrm{CHX}$ at a specific $\mathrm{pH}$. The concentration of the released $\mathrm{CHX}$ was measured using UV-Visible spectrophotometer. All experiments were carried out in triplicate and the percentage of cumulative drug release was calculated.

\section{Surface functionalization of CLC with PDAC}

We used the cationic polyelectrolyte PDAC to reverse the surface charge of the Carbopol Aqua SF1 nanogel particles from negative to positive which promotes adhesion to the microbial cell walls. PDAC solutions with a range of different concentrations (0.001-0.01 wt\%) were mixed separately with a fixed concentration of the nanogel $(0.1 \mathrm{wt} \%)$ at a $\mathrm{pH}$ adjusted in the range of 4.75-5.00 using acetate buffer with the final volume of the suspension being $10 \mathrm{~mL}$. The zeta potential was measured for each sample to find out the optimum concentration of both the PDAC and the nanogel which in turn give stable suspension. Typically, a $1.10 \mathrm{~mL}$ aliquot of $0.2 \mathrm{wt} \%$ PDAC solution was rapidly added to a suspension of $10 \mathrm{~mL}$ of the CLC suspension with vigorous shaking and then diluted to $20 \mathrm{~mL}$ to form PDAC-coated 0.005 wt\% $\mathrm{CHX}$-loaded $0.1 \mathrm{wt} \%$ Carbopol Aqua SF1 nanogel dispersion (PDAC-coated CLC). The resulting solution was used as a stock to study its antimicrobial effect on C. reinhardtii, S. cerevisiae, E. coli and S. aureus. 

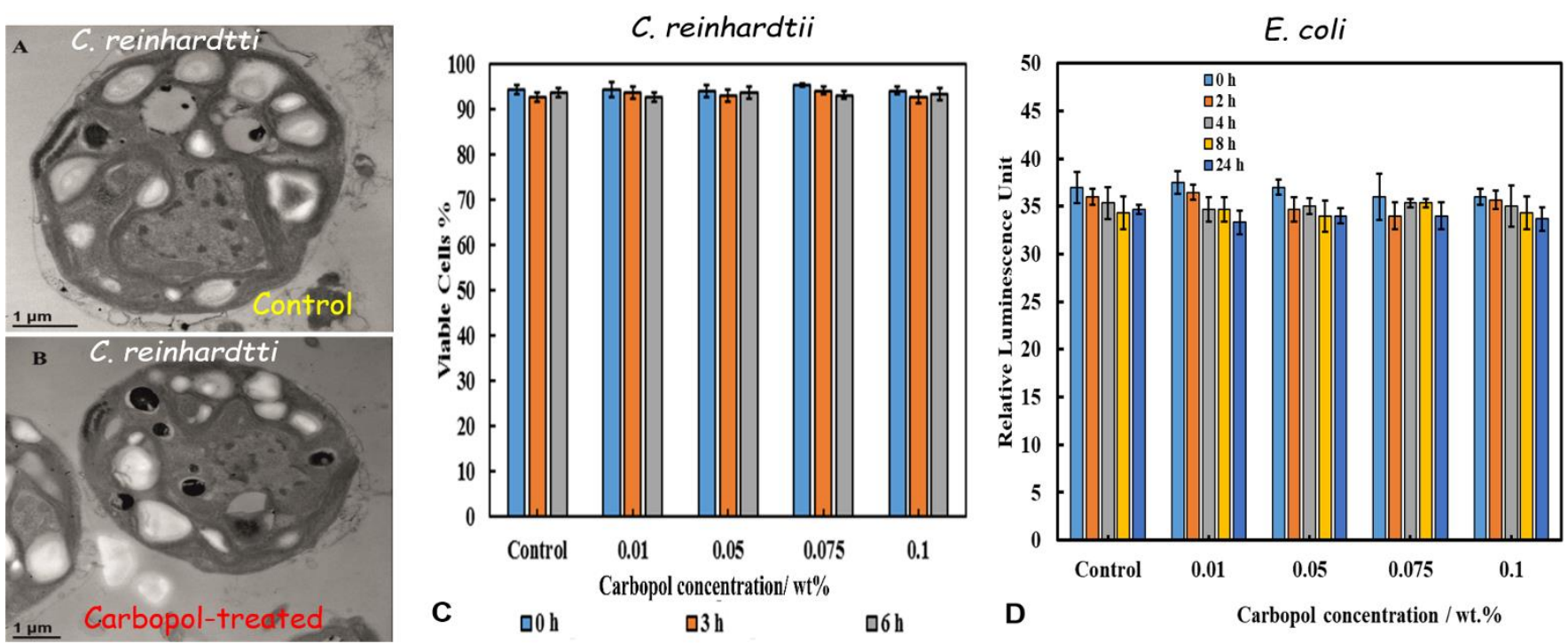

Figure 4. TEM images of sectioned C. reinhardtii cells (A) as control sample without prior treatment and (B) after incubation with $0.1 \%$ Carbopol Aqua SF1 nanogel followed by washing, negative staining and embedding in acrylic resin. The cell viability of $C$. reinhardtii (C) and $E$. coli (D) incubated in aqueous suspensions of varying concentrations of the nanogel at $25^{\circ} \mathrm{C}$ at pH 5.5 for different periods of time. The cell viability was tested with FDA live/dead assay for C. reinhardtii and Promega CellTiter-Glo ${ }^{\otimes}$ assay for E. coli, respectively.

\section{Cytotoxicity test of the non-coated Carbopol nanogel particles}

A cell viability assay was performed to determine the cytotoxicity of the Carbopol Aqua SF1 nanogel on both of $C$. reinhardtii and E. coli. A 0.3 wt\% dispersion of Carbopol Aqua SF1 was prepared in a $100 \mathrm{ml}$ volumetric flask by dilution of an aliquot of the supplied stock with milli- $\mathrm{Q}$ water. The $\mathrm{pH}$ was adjusted to 5.5 using acetate buffer. $5 \mathrm{~mL}$ aliquots of the cell suspension were washed from the culture media and incubated with a series of $5 \mathrm{~mL}$ aliquots of the nanogel dispersion of concentrations (0.01-0.15 wt\%) and tested at different incubation times. The control sample was treated in the same way without incubation with the nanogel. The cell viability was examined as described below.

\section{Testing the effect of PDAC-coated CLC on C. reinhardtii}

C. reinhardtii was cultured in media containing $2.42 \mathrm{~g}$ Tris, 25 $\mathrm{mL}$ TAP salts, $375 \mu \mathrm{L}$ phosphate solution, $1000 \mu \mathrm{L}$ Hunter's trace element, and $1000 \mu \mathrm{L}$ glacial acetic acid per $1 \mathrm{~L}$ of Milli-Q water. A $50 \mathrm{~mL}$ aliquot was removed from the culture for viability testing. This was centrifuged at $3000 \mathrm{rpm}$ for 3 minutes to pellet the cells, the supernatant was discarded and the cells redispersed in $50 \mathrm{~mL}$ of fresh Milli-Q water by gentle shaking. Fluorescein diacetate (FDA) is a non-polar esterified compound which easily diffuses through the cell membranes. If the cell is viable and its membrane is intact the hydrolysis of the nonfluorescent precursor (FDA) by intracellular esterase leads to accumulation of fluorescein. We used $0.5 \% \mathrm{w} / \mathrm{v}$ FDA dissolved in acetone. $20 \mu \mathrm{L}$ of this solution was used per $\mathrm{mL}$ of cell sample. The tube with the mixture was shaken for 10 minutes using a vortex at $1500 \mathrm{rpm}$ in dark conditions to avoid the photobleaching of the produced fluorescein inside the viable cells. This was repeated for cells incubated at room temperature for 1 and 2 hours. The cell viability was measured using a Cellometer Auto X 4 cell counter. $20 \mu \mathrm{L}$ of the sample was loaded into a disposable plastic counting chamber and the fluorescing (viable) and non-fluorescing (non-viable) cells measured using bright field and fluorescent microscopy imaging. This was repeated three times to obtain an average. When a cell viability above $85 \%$ was measured then the original $50 \mathrm{~mL}$ stock sample was used for further testing. $5 \mathrm{~mL}$ aliquots were of this stock were mixed with $5 \mathrm{~mL}$ aliquots of various treatments for 0 hours ( 5 minutes), 1 hour and 2 hours, respectively. We tested the $C$. reinhardtii cell viability in the following solutions:

(i) 0.005 wt $\%$ PDAC;

(ii) 0.005 wt\% PDAC-coated 0.1 wt\% Carbopol (no CHX);

(iii) $0.1 \mathrm{wt} \% \mathrm{CHX}$ (chlorhexidine digluconate);

(iv) 0.1 wt\% encapsulated $\mathrm{CHX}$ in $0.1 \%$ Carbopol (CLC);

(v) 0.005 wt\% PDAC - coated 0.1 wt\% CHX-loaded in $0.1 \%$ Carbopol (PDAC-coated CLC).

After incubation of the microalgae cell sample with these solutions, an aliquot was again centrifuged at $3000 \mathrm{rpm}$ for 5 minutes and excess treatment washed away. The cells were resuspended in $1 \mathrm{~mL}$ of Milli-Q water. C. reinhardtii cell viability was measured by using $20 \mu \mathrm{L}$ of this cell suspension in a Cellometer Auto X4.

\section{Testing the effect of PDAC-coated CLC on S. cerevisiae}

S. cerevisiae was cultured in media containing $20 \mathrm{~g}$ peptone, 10 g yeast extract, $20 \mathrm{~g}$ D-glucose per $1000 \mathrm{~mL}$ Milli-Q water. 0.01 $\mathrm{g}$ of dried S. cerevisiae was added per $100 \mathrm{~mL}$ of media. A 50 $\mathrm{mL}$ aliquot was removed from the culture for viability testing. This was centrifuged at $3000 \mathrm{rpm}$ for 3 minutes to pellet the cells, the supernatant was discarded and the cells dispersed in $50 \mathrm{~mL}$ of fresh Milli-Q water by gentle shaking. $1 \mathrm{~mL}$ of washed 
S. cerevisiae sample was pipetted into a sample tube and $20 \mu \mathrm{L}$ of the FDA stock solution in acetone was added and the mixture was incubated at room temperature in dark conditions. This was repeated for cells incubated at room temperature for 1 hour and 2 hours. The viability was measured using a Cellometer Auto $\mathrm{X} 4$ cell counter as described previously for $C$. reinhardtii.

\section{Testing the effect of PDAC-coated CLC on E. coli}

We prepared $300 \mathrm{~mL}$ of $E$. coli cultured in LB media. $50 \mathrm{~mL}$ was aliquoted and subsequently centrifuged at $3000 \mathrm{rpm}$ for 5 minutes. The supernatant was discarded, and the cell pellet resuspended in $50 \mathrm{~mL}$ of milli-Q water. Various concentrations of treatment formulations were created in $5 \mathrm{~mL}$ aliquots (see Table 1) by dilution from the stock solution of $0.0025 \mathrm{wt} \%$ PDAC - coated 0.05 wt\% CHX-Carbopol. $5 \mathrm{~mL}$ of the $E$. coli culture (redispersed in Milli-Q water) was added to $5 \mathrm{~mL}$ of the various formulations and gently shaken by hand to mix. The E. coli and formulation aliquots (total $10 \mathrm{~mL}$ ) were incubated for 0 hours (5 $\min ), 1$ hour and 2 hours, respectively under the same conditions as for the original E. coli culture. Post incubation the E. coli and treatment aliquot was centrifuged at $3000 \mathrm{rpm}$ for 5 minutes and the supernatant discarded (removing access $\mathrm{CHX}$ and halting the cell viability experiment). The cell pellet was resuspended in $1 \mathrm{~mL}$ of Milli-Q water by gentle shaking. $100 \mu \mathrm{L}$ aliquot of each sample was pipetted into white opaque 96 well plate and immediately afterwards $100 \mu \mathrm{L}$ Promega Cell Titer$\mathrm{Glo}^{\circledR}$ luminescent cell viability assay reagent was added. The mixture of sample and reagent was equilibrated at room temperature for 30 minutes as stated in the manufacturer's protocol. The luminance was measured using a Thermo Scientific Fluroskan Ascent FL.

\section{Protocol for SEM imaging of the treated cells}

The microbial cells to be studied were removed from their culture media by washing PBS buffer, adhered to Aclar film, and then fixed in 2.5 wt\% glutaraldehyde in $0.1 \mathrm{M}$ cacodylate buffer $\mathrm{pH} 7.2$ for 2 hours at room temperature. Then, they were washed three times with cacodylate buffer and fixed in 1 wt\% osmium tetroxide in cacodylate buffer for 1 hour. Finally, the cells were washed with cacodylate buffer, dehydrated in a series of ethanol-water solutions with decreasing water content and then dried using liquid carbon dioxide at its critical point.

\section{MIC and MBC of CHX and PDAC-coated CLC on S. aureus}

The following protocol was used to determine the Minimal Inhibitory Concentration (MIC) and the Minimal Bactericidal Concentration (MBC) of $\mathrm{CHX}$ and PDAC-coated $\mathrm{CLC}$ on S. aureus. A negative control of $100 \mu \mathrm{L}$ of $\mathrm{MHB}$ (Muller Hinton Broth) was added to the first line of wells of a 96 well plate. $50 \mu \mathrm{L}$ of $\mathrm{MHB}$ was added to the treatment wells and the positive bacteria control wells. A stock solution of $\mathrm{CHX}$ and PDAC-coated CLC was created in fresh MHB to a total volume of $10 \mathrm{~mL}$. $50 \mu \mathrm{L}$ of this formulation was added to the first line of treatment wells, and serial diluted 1:2 across the 96 well plate, ensuring it was mixed by pipetting up and down within each well. An overnight culture of $S$. aureus was diluted into sterilised $0.85 \%$ saline until an absorbance reading of between 0.08-0.12 at $625 \mathrm{~nm}$ was obtained on a spectrophotometer (0.5 Mcfarland Standard). The saline diluted bacteria was diluted further 1:150 into $\mathrm{MHB}$ (10 $\mathrm{mL} \mathrm{MHB}+66.67 \mu \mathrm{L}$ of bacteria in saline solution) yielding a $10 \mathrm{~mL}$ stock containing $5 \times 10^{5}-1 \times 10^{6} / \mathrm{mL}$ cells. $50 \mu \mathrm{L}$ from this bacteria stock was added to each treatment and positive bacteria control wells, seeding with $2.5 \times 10^{4}-5 \times 10^{4}$ cells per well. Each well contained a final volume of $100 \mu \mathrm{L}$ with decreasing concentrations of treatment on equal amounts of bacteria. The plate was incubated for 20 hours at $37^{\circ} \mathrm{C}$. After incubation, $20 \mu \mathrm{L}$ of resazurin solution was added to each well, and the plate incubated for 3 hours at $37^{\circ} \mathrm{C}$. The resazurin solution was formulated by dissolving resazurin powder into DPBS at $0.15 \mathrm{mg} / \mathrm{mL}$. The plate was then colometrically measured at $570 \mathrm{~nm}$ excitation / $595 \mathrm{~nm}$ emission. The reading from the negative control wells was subtracted from the remaining wells to remove background absorbance. The MIC was determined by from the lowest concentration treatment which inhibited growth.

\section{S. aureus time kill assay}

Antimicrobial activity of $0.1 \%$ free $\mathrm{CHX}$ and $0.1 \% \mathrm{CHX}$ encapsulated in CLC after PDAC-functionalisation was tested against S. aureus (ATCC number 29213). An overnight culture of $S$. aureus was diluted in $\mathrm{MHB}$ to a population of $5 \times 10^{5}-1 \times$ $10^{6} \mathrm{CFU} / \mathrm{mL}$, and treated with antimicrobial formulations at $37^{\circ} \mathrm{C}$. At selected time points $100 \mu \mathrm{L}$ aliquots were removed, neutralised in Dey-Engley Broth and serially diluted for colony enumeration. The control received no treatment. This was added to the $5 \mathrm{~mL}$ bacterial sample creating a $10 \mathrm{~mL}$ aliquot containing $5 \times 10^{5}-1 \times 10^{6} / \mathrm{mL} \mathrm{CFU}$ and $0.1 \mathrm{wt} \% \mathrm{CHX}$ in $0.005 \mathrm{wt} \%$ PDAC-coated CLC encapsulated chlorhexidine. The three aliquots of were placed into a shaking rack and incubated at $37^{\circ} \mathrm{C}$ for $24 \mathrm{hrs} .100 \mu \mathrm{L}$ (from the $10 \mathrm{~mL}$ test sample yields $5 \times$ $10^{4}-1 \times 10^{5} \mathrm{CFU} / 100 \mu \mathrm{L}$ ) of each of the aliquots were removed at specific time points, $0 \mathrm{hr}, 30 \mathrm{~min}, 1,2,3,6$ and 24 hours. The $100 \mu \mathrm{L}$ sample that was removed was serial diluted in neutralising Dey-Engley broth and plated onto agar at $10^{2}, 10^{3}$, $10^{4}, 10^{5}, 10^{6}, 10^{7}$ dilutions depending on the time point $(100 \mu \mathrm{L}$ spread on agar $x 3$ repeats). The plates were incubated at $37^{\circ} \mathrm{C}$ and enumerated 24 hours later.

\section{Results and Discussion}

\section{Encapsulation of CHX into Carbopol Aqua SF1 nanogel}

We used a $\mathrm{pH}$ mediated swelling/deswelling method to encapsulate $\mathrm{CHX}$ cations in the core of the acrylate copolymer nanogel particles. Figure $2 \mathrm{~A}$ shows the increase of the nanogel particle size with the increase of $\mathrm{pH}$. Here we enclose details of the swelling behaviour of the Carbopol nanogel before and after loading with $\mathrm{CHX}$. The non-loaded Carbopol nanogel particles have an average diameter of about $100 \mathrm{~nm}$ at a pH below 6.8 and swells sharply to approximately $330 \mathrm{~nm}$ just above $\mathrm{pH} 7$. 

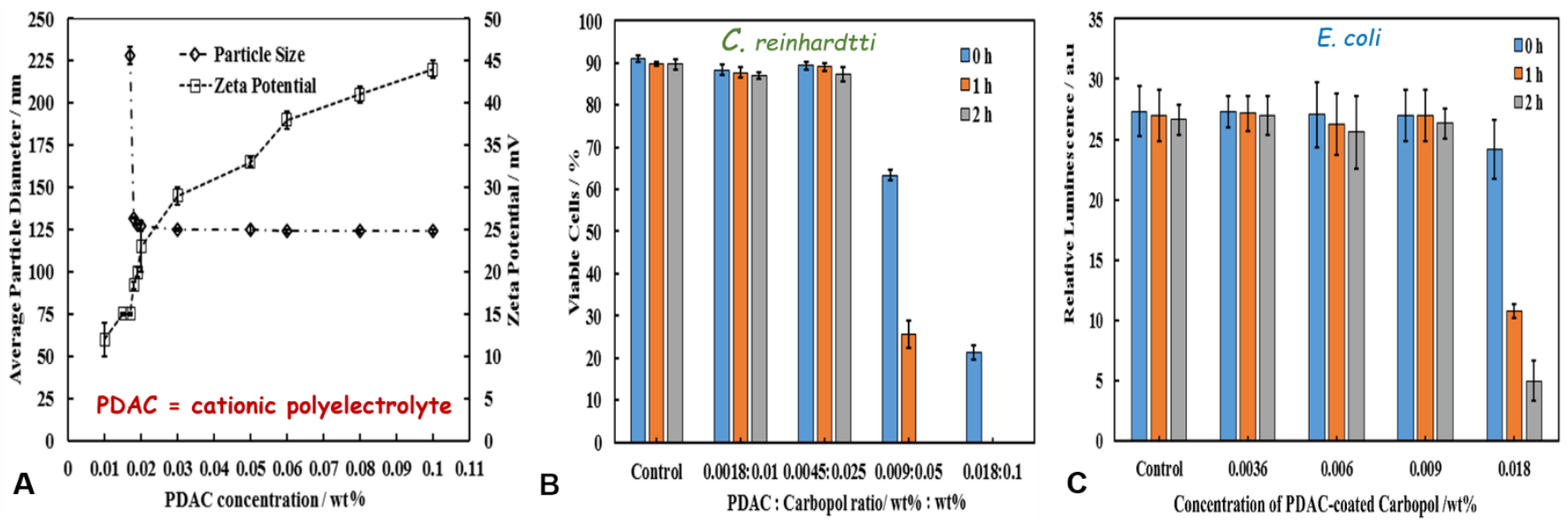

Figure 5. All data on this figure characterise the non-loaded Carbopol nanogel after coating with PDAC. (A) The average particle hydrodynamic diameter and zeta-potential of PDACcoated Carbopol Aqua SF1 suspension as a function of the PDAC concentration which were obtained by mixing solutions of varying concentration of PDAC with 0.1 wt\% Carbopol nanogel. The cytotoxic effect of PDAC-coated Carbopol Aqua SF1 particles at different ratios of PDAC-to-Carbopol on (B) C. reinhardtii and (C) E. coli for up to 2 hours at $25^{\circ} \mathrm{C}$.

The swelling/deswelling feature of the Carbopol microgel was exploited for the purposes of development of $\mathrm{CHX}$ delivery system. This microgel was therefore used to encapsulate chlorhexidine digluconate with the aim of targeted delivery to microbial cells. The size of the collapsed Carbopol nanogel particles was also confirmed by TEM imaging (Figure 2B). Above $\mathrm{pH} 7$ the Carbopol Aqua SF1 nanogel particles swell as the carboxyl groups of the acrylate-copolymer are deprotonated to a higher degree which allows the $\mathrm{CHX}$ cations to interact and bind with them electrostatically. This was then followed by a $\mathrm{pH}$ drop to 5.5 which causes shrinkage of the $\mathrm{CHX}$-loaded nanogel particles (CLC), which are then centrifuged to separate them from the free $\mathrm{CHX}$. The $\mathrm{pH}$ of the $\mathrm{CLC}$ suspension was raised to $\mathrm{pH} 8$ so that the particles in the pellet swell and re-disperse again. This was followed by de-swelling the redispersed particles at pH 5.5 using acetate buffer. This procedure yielded fully dispersed and stable suspension of $\mathrm{CHX}$-loaded Carbopol nanogel. Figure $2 \mathrm{C}$ illustrates the visual appearance of the nanogel suspension at different stages of the loading with the $\mathrm{CHX}$ and their successful re-dispersing in water.

\section{Effect of the $\mathrm{CHX}$ concentration on the CLC nanocarrier stability}

After encapsulation of the $\mathrm{CHX}$ in the swollen nanogel particles and their shrinking at $\mathrm{pH} 5$, the size of the loaded (CLC) particles depends on both the initial $\mathrm{CHX}$ and Carbopol concentration. The effect of different concentrations of chlorhexidine on the colloidal stability of the $0.1 \mathrm{wt} \%$ Carbopol Aqua SF1 was investigated. Figure $2 \mathrm{E}$ shows the increase of the nanogel particle size after loading with $\mathrm{CHX}$. The particle size increase is an indication for partial aggregation at high $\mathrm{CHX}$-to-Carbopol ratio. Therefore we choose to work at $0.1 \mathrm{wt} \%$ Carbopol initial concentration and a moderate $\mathrm{CHX}$-to-Carbopol ratio as it only marginally increased the size of the collapsed CLC nanogel particles at $\mathrm{pH} 5.5$ across the full range of $\mathrm{CHX}$ concentrations (Figure $2 \mathrm{E}$ ). At higher $\mathrm{CHX}$ concentrations ( $0.1 \mathrm{wt} \%$ ), the average hydrodynamic diameter of the collapsed CLC particles appeared to be $135 \mathrm{~nm}$ without significant particle aggregation. The loading of the nanogel particles with $\mathrm{CHX}$ did not seem to significantly change the zeta potential of the collapsed $\mathrm{CHX}$ loaded nanogel (CLC) as a function of the $\mathrm{CHX}$ initial concentration, which remained negative in the range -(25-30) $\mathrm{mV}$ (Figure 2E).

\section{Spectroscopy studies of the CLC nanogel particles}

FTIR spectra were obtained for Carbopol, CHX, CHX-loaded Carbopol (CLC). For Carbopol (Figure 3A), a characteristic peak was seen in the range $3300-3500 \mathrm{~cm}^{-1}$ due to the stretching vibrations of $\mathrm{O}-\mathrm{H}$ and intermolecular hydrogen bonding. The strong peak between $2850 \mathrm{~cm}^{-1}$ and $3000 \mathrm{~cm}^{-1}$ is due to the stretching vibration band of the aliphatic $\mathrm{C}-\mathrm{H}$ bond. The peak in the range $1670-1750 \mathrm{~cm}^{-1}$ is attributed to a strong vibration band of carbonyl stretching $(\mathrm{C}=\mathrm{O})$ while the two variable peaks at $1400-1490 \mathrm{~cm}^{-1}$ were assigned to the stretching vibration band of the carbonyl bond (C-O). The peak appearing from 1000 $-1300 \mathrm{~cm}^{-1}$ was attributed to the coupling between in-plane $\mathrm{O}$ $\mathrm{H}$ bending and $\mathrm{C}-\mathrm{O}$ stretching of neighbouring carboxyl groups. ${ }^{34,35}$ The spectrum of $\mathrm{CHX}$ (Figure $3 \mathrm{~B}$ ) is characterized by the main stretching vibrations from $3300 \mathrm{~cm}^{-1}$ to $3500 \mathrm{~cm}^{-1}$ for the $\mathrm{N}-\mathrm{H}$ group. The bands at $2850 \mathrm{~cm}^{-1}$ to $3000 \mathrm{~cm}^{-1}$ are stretching vibration bands due to the aliphatic $\mathrm{C}-\mathrm{H}$ group, while the peak at $1672 \mathrm{~cm}^{-1}$ relates to the stretching vibration band of the aliphatic $\mathrm{C}=\mathrm{N}$ group which is considered as a characteristic peak of $\mathrm{CHX}$. There are also a peaks at wavelengths from 1450 $\mathrm{cm}^{-1}$ to $1550 \mathrm{~cm}^{-1}$ which are assigned to $\mathrm{C}=\mathrm{C}$ group in the aromatic ring and at $1251 \mathrm{~cm}^{-1}$ which relates to the stretching vibration frequency of aliphatic amine (C-N) group. ${ }^{36-38}$ Figure $3 \mathrm{C}$ shows the FTIR spectrum of CLC. The broad absorption band at $3435 \mathrm{~cm}^{-1}$ can be allocated to the $\mathrm{O}-\mathrm{H}$ groups for Carbopol while the band at $3364 \mathrm{~cm}^{-1}$ for the $\mathrm{N}-\mathrm{H}$ group for chlorhexidine. 

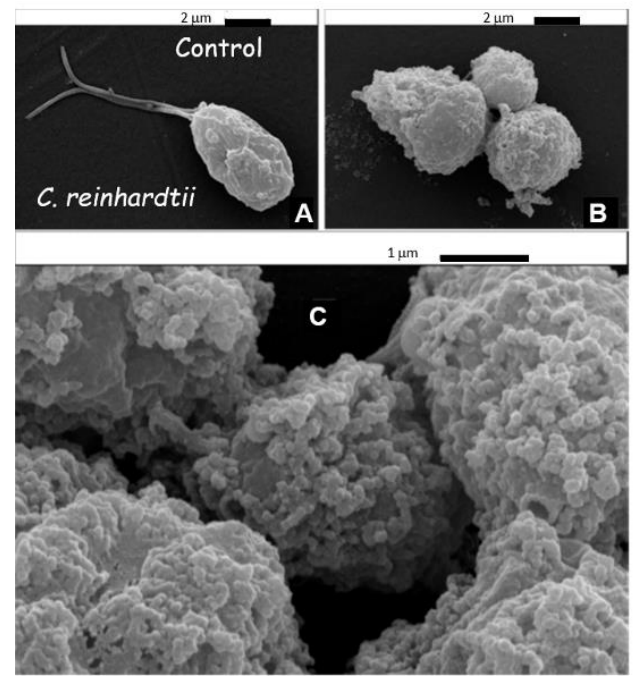
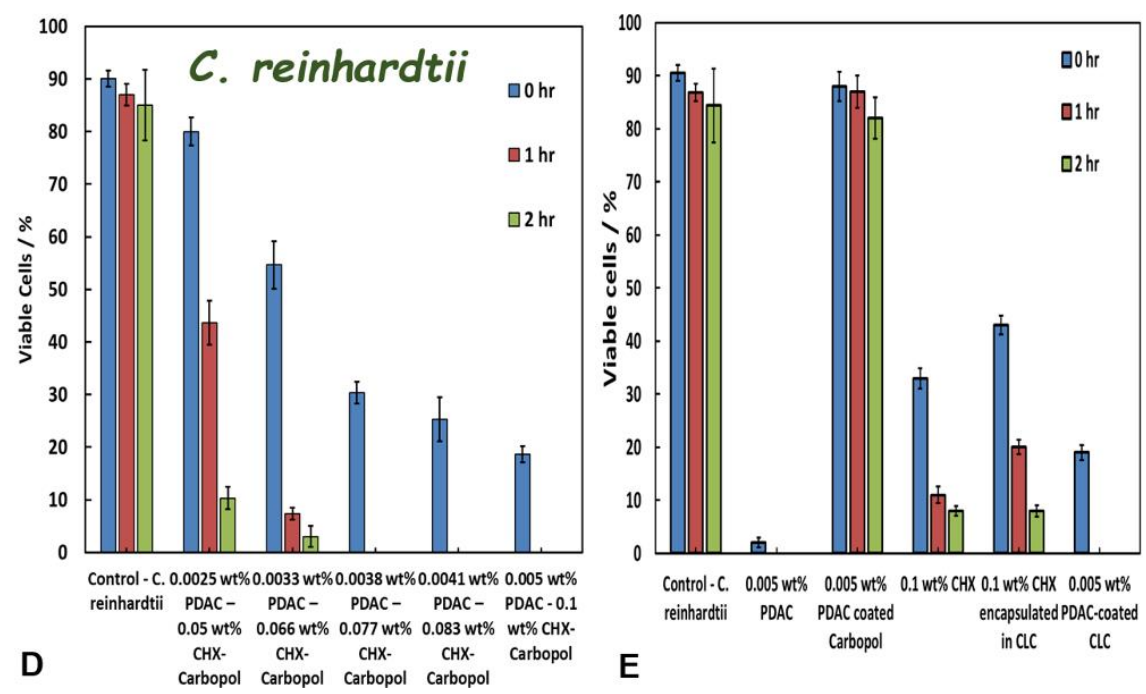

Figure 6. SEM images of $C$. reinhardtii cells with (A) being the control sample of untreated $C$. reinhardtii, (B) and (C) samples of $C$. reinhardtii after incubation in a suspension of 0.005 wt\% PDAC- 0.0225 wt\% CHX-Carbopol Aqua SF1 suspension for 1 hour. (D) The viability of $C$. reinhardtii cells after timed exposure to antimicrobial formulations of PDAC-coated CLC at different concentrations for various time points (0, 1, 2 hours). The solutions are prepared by gradual dilution of a stock of 0.005 wt $\%$ PDAC-coated 0.1 wt $\%$ CHX loaded in 0.1 wt $\%$ Carbopol (CLC). (E) The viability of $C$. reinhardtii cells after timed exposure to antimicrobial formulations in Milli-Q water for various time points $(0,1,2$ hours). The graph compares the anti-algal activity of 0.005 wt\% PDAC, 0.005 wt\% PDAC coated Carbopol Aqua SF1 nanogel, 0.1 wt\% CHX, 0.1 wt\% CLC and 0.005 wt\% PDAC-coated 0.1 wt\% CLC. The cell viability was tested with FDA live/dead assay in a Cell counter.

The frequencies at $1653 \mathrm{~cm}^{-1}$ and $1734 \mathrm{~cm}^{-1}$ were noticed as principal characteristic bands for $\mathrm{CHX}$-loaded Carbopol Aqua SF1 as they represent the vibration bands of the aliphatic $\mathrm{C}=\mathrm{N}$ group for $\mathrm{CHX}$ and the carbonyl group $(\mathrm{C}=\mathrm{O})$ for Carbopol, respectively. The FTIR spectra therefore confirm that the $\mathrm{CHX}$ was successfully encapsulated into Carbopol Aqua SF1 nanogel. This result were also supported by TGA (Figure 3E) and the UVvis spectrum data for CLC (Figure 3F). The UV-vis absorption spectrum of Carbopol Aqua SF1, CHX and CLC indicate the physical conjugation between Carbopol Aqua SF1 and CHX. It can be seen that Carbopol Aqua SF1 (blue line) absorbs in the UV region between $250 \mathrm{~nm}$ to $200 \mathrm{~nm}$. $\mathrm{CHX}$ (orange line) has two broad absorbance peaks in the UV region, one at $254 \mathrm{~nm}$ and another at $233 \mathrm{~nm}$. The CLC (black line) exhibited two substantial peaks at $264 \mathrm{~nm}$ and $233 \mathrm{~nm}$ confirming the presence of intercalated $\mathrm{CHX}$ into the Carbopol nanogel particles. The presence of PDAC was not possible to detect from the FTIR spectra of the PDAC-coated CLC as the PDAC it is in negligible amount (Figure 3D). There are no characteristic peaks from PDAC on the FTIR spectrum of the PDAC-coated CLC. However, the zeta-potential measurements confirm its presence as it reverses from negative for CLC to positive (Figure $2 \mathrm{E})$ upon coating with PDAC.

\section{Elemental (CHN) analysis of CLC}

Table 1 shows the wt\% of $\mathrm{C}, \mathrm{H}$ and $\mathrm{N}$ for Carbopol Aqua SF1 and CHX-loaded in Carbopol Aqua SF1 (CLC) per dry weight. The percentage of encapsulated $\mathrm{CHX}$ can vary depending on the initial $\mathrm{CHX}$ concentration used during the encapsulation process with the Carbopol nanogel. $\mathrm{CHN}$-analysis data showed that the percentage of $\mathrm{CHX}$ into the $\mathrm{CLC}$ was about $13.2 \mathrm{wt} \%$ (per dry weight of $\mathrm{CLC}$ ). The mole ratio of $\mathrm{COOH}$-group (in Carbopol) to $\mathrm{CHX}$ was found to be about 50. In this estimate we have assumed that the Carbopol composition corresponds to polyacrylic acid. This explains why the $\mathrm{CHX}$-loaded Carbopol (CLC) particles still carry negative surface charge (negative zeta potential) which is due to the dominance of the nanogel $\mathrm{COOH}$ groups over the positive charge brought by the $\mathrm{CHX}$.

Table 1. The elemental analysis of Carbopol Aqua SF1 and the encapsulated chlorhexidine (CHX) into Carbopol Aqua SF1 microgel through centrifuging and drying the each sample in air at room temperature.

\begin{tabular}{ccc}
\hline Element & \% in Carbopol Aqua SF1 & \% in CLC \\
\hline C & 56.73 & 53.59 \\
H & 4.99 & 7.35 \\
N & 0.00 & 3.67 \\
The \% drug content in Carbopol Aqua SF1 & 13.2 \\
\multicolumn{2}{r}{ Mole Ratio (COOH /CHX) } & 50.2 \\
\hline
\end{tabular}

\section{Release kinetics of CHX from CLC}

Our $\mathrm{CHX}$ release experiments done under sink conditions showed that the CLC nanogel particles can slowly release free $\mathrm{CHX}$ upon multiple dilution with water (see Figure $3 \mathrm{G}$ ) over the course of 24 hours. The $\mathrm{CHX}$ release rate from the nanogel depends on the $\mathrm{pH}$ of the surrounding medium. At $\mathrm{pH} 5.5$, approximately $13 \%$ of the encapsulated $\mathrm{CHX}$ was released after 2 hours while $17 \%$ of the total encapsulated amount was released after 5 hours. At pH 7.5, 20\% of the $\mathrm{CHX}$ was released out of the nanogel after 2 hours and $25 \%$ after 5 hours. The sustained release of $\mathrm{CHX}$ from the nanogel particles could be beneficial in many antimicrobial applications where $\mathrm{CHX}$ concentration has to be supported in the surrounding media for a long period of time. The higher rate of release of $\mathrm{CHX}$ at the higher $\mathrm{pH}$ can be explained by the partial swelling of the nanogel which facilitates the $\mathrm{CHX}$ diffusion and intercalation within the particles interior. 

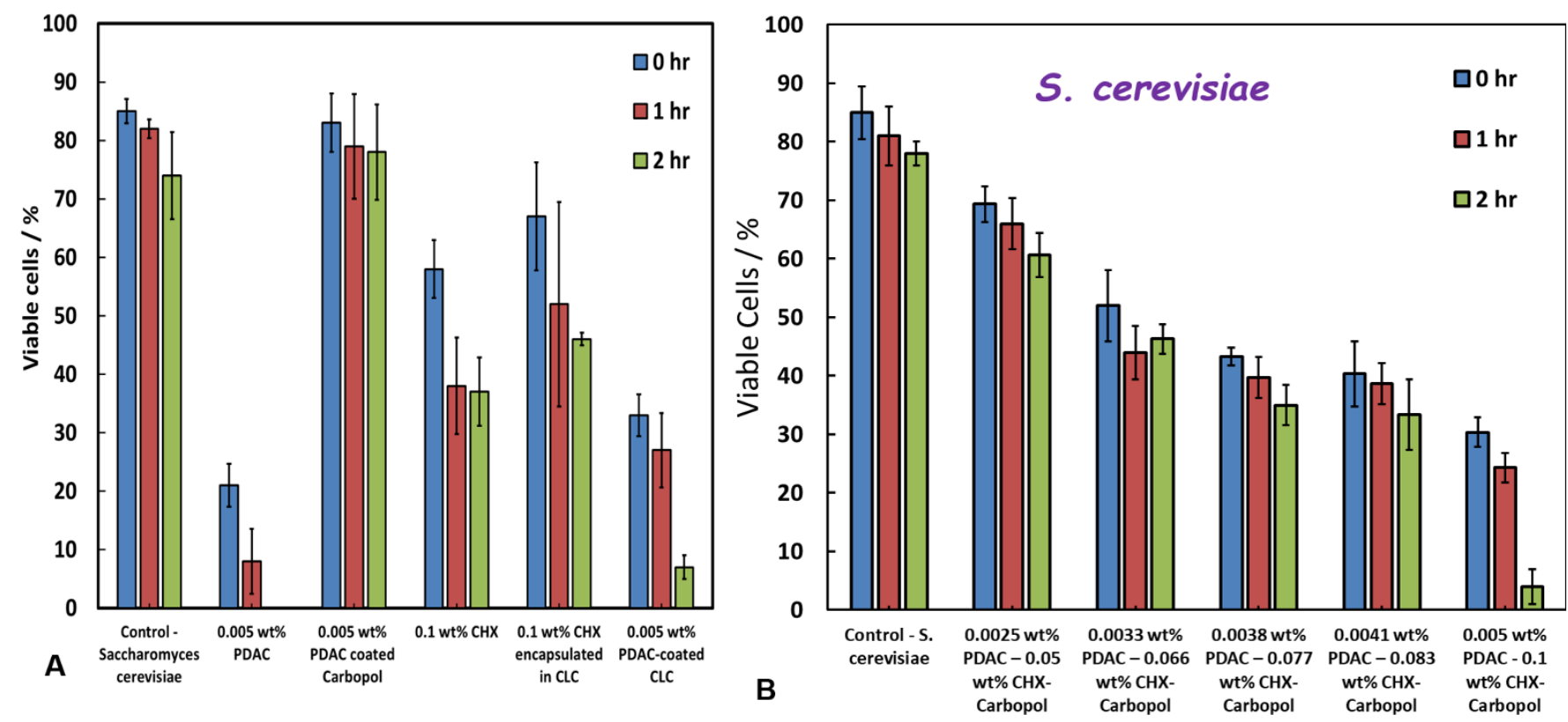

Figure 7. (A) The viability of $S$. cerevisiae cells after exposure to different antimicrobial formulations in Milli-Q water for several incubation times ( $0,1,2$ hours). The graph compares the anti-yeast activity of 0.005 wt\% PDAC, 0.005 wt\% PDAC coated Carbopol Aqua SF1 nanogel, 0.1 wt $\%$ CHX, 0.1 wt $\%$ CLC and 0.005 wt\% PDAC-coated 0.1 wt $\%$ CLC. (B) The viability of $S$. cerevisiae cells after exposure to formulations of PDAC-coated CLC at different concentrations for various incubation times ( $0,1,2$ hours). The solutions are prepared by gradual dilution of a stock of 0.005 wt \% PDAC-coated 0.1 wt $\%$ CHX loaded in $0.1 \mathrm{wt} \%$ Carbopol (CLC). The yeast cell viability was tested with FDA live/dead assay in a cell counter.

\section{Toxicity assay of the non-coated Carbopol nanogel particles}

Two test microorganisms, C. reinhardtii (microalgae) and E. coli, were incubated with Carbopol Aqua SF1 suspensions of different concentrations of nanogel particles. The cells were removed from the culture media to avoid any interaction between the nanogel particles and the components of culture media. The morphology of $C$. reinhardtii after incubation with the nanogel was studied by TEM. Figure 4B shows TEM images of sectioned microalgae cells after incubation for 24 hours with 0.1 wt\% Carbopol nanogel at $\mathrm{pH}$ 5.5. The cell wall and the internal microstructure the Carbopol nanogel-treated microalgae do not indicate visible disruption compared with the control microalgae (Figure 4A). Cell viability assay (Figure 4C) does not indicate any cytotoxic effect of the non-loaded Carbopol Aqua SF1 on C. reinhardtii for a wide range of Carbopol Aqua SF1 concentrations at room temperature and up to 6 hours of incubation. Figure 4D also shows no pronounced cytotoxic effect of the Carbopol nanogel on E. coli cells for up to 24 hours. Similar results (not presented here) were also obtained for S. cerevisiae. These data are in agreement with the manufacturer's technical data for other microorganisms. ${ }^{31}$

\section{Effect of PDAC-functionalization on Carbopol nanogel stability and toxicity}

Figure $5 A$ shows the average particle hydrodynamic diameter of the PDAC-coated Carbopol Aqua SF1 nanogels as a function of the PDAC-concentration. PDAC- coated Carbopol particles show good colloidal stability up to 0.03 wt\% PDAC with zetapotentials ranging from $+12 \mathrm{mV}$ for $0.017 \mathrm{wt} \%$ PDAC to $+44 \mathrm{mV}$ for 0.1 wt\% PDAC at $\mathrm{pH}$ 5.5. This result shows that upon coating with PDAC, the surface charge of the Carbopol nanocarrier has changed from negative (bare Carbopol) to positive giving cationic particles. We measured the zeta-potential of $0.005 \%$ PDAC-coated $0.1 \%$ carbopol over an interval of over 24 hours and did not find any measurable change, as it stayed around $+25 \pm 2 \mathrm{mV}$ at $\mathrm{pH} 5.5$ (see Figure $2 \mathrm{D}$ ). Figures $5 \mathrm{~B}$ and $5 \mathrm{C}$ show the FDA viability assay for $C$. reinhardtii and $E$.coli upon incubation with the PDAC-coated nanogel without CHX. One can see that the nanocarrier shows measurable toxicity above $0.009 \mathrm{wt} \%$ PDAC for C. reinhardtii and above $0.018 \mathrm{wt} \%$ for $E$.coli. In order to distinguish between the toxicity of the PDAC-coating and the antimicrobial action of the $\mathrm{CHX}$, we chose to work at concentrations of 0.005 wt\% PDAC for which the "empty" nanocarrier is non-toxic to both microorganisms. Therefore, any further manifestation of antimicrobial action of 0.005 wt\% PDAC-coated CLC would be solely due to delivery of $\mathrm{CHX}$ rather than effect of the PDAC coating of the nanocarrier.

\section{Anti-algal action of PDAC-coated CLC on C. reinhardtii}

The antimicrobial activity of $\mathrm{CHX}$ with $\mathrm{C}$. reinhardtii was examined by incubation of the microalgae cells for up to 2 hours in PDAC-coated CHX-loaded Carbopol nanogel suspensions of different concentrations. Figures $6 \mathrm{~B}$ and $6 \mathrm{C}$ shows SEM images of C.reinhardtii cells which have been incubated with a suspension of 0.005 wt\% PDAC-0.0225 wt\% CHX-0.1 wt\% Carbopol for 1 hour. The SEM image in Figure 6A shows the morphology of the control sample of untreated microalgae. One can see that the cationic nanogel particles have accumulated on the cell wall of the treated microalgae. Figure $6 \mathrm{C}$ shows a high magnification SEM image which visualises the heterocoagulation of the $\mathrm{CHX}$-loaded nanocarrier on the cells. 

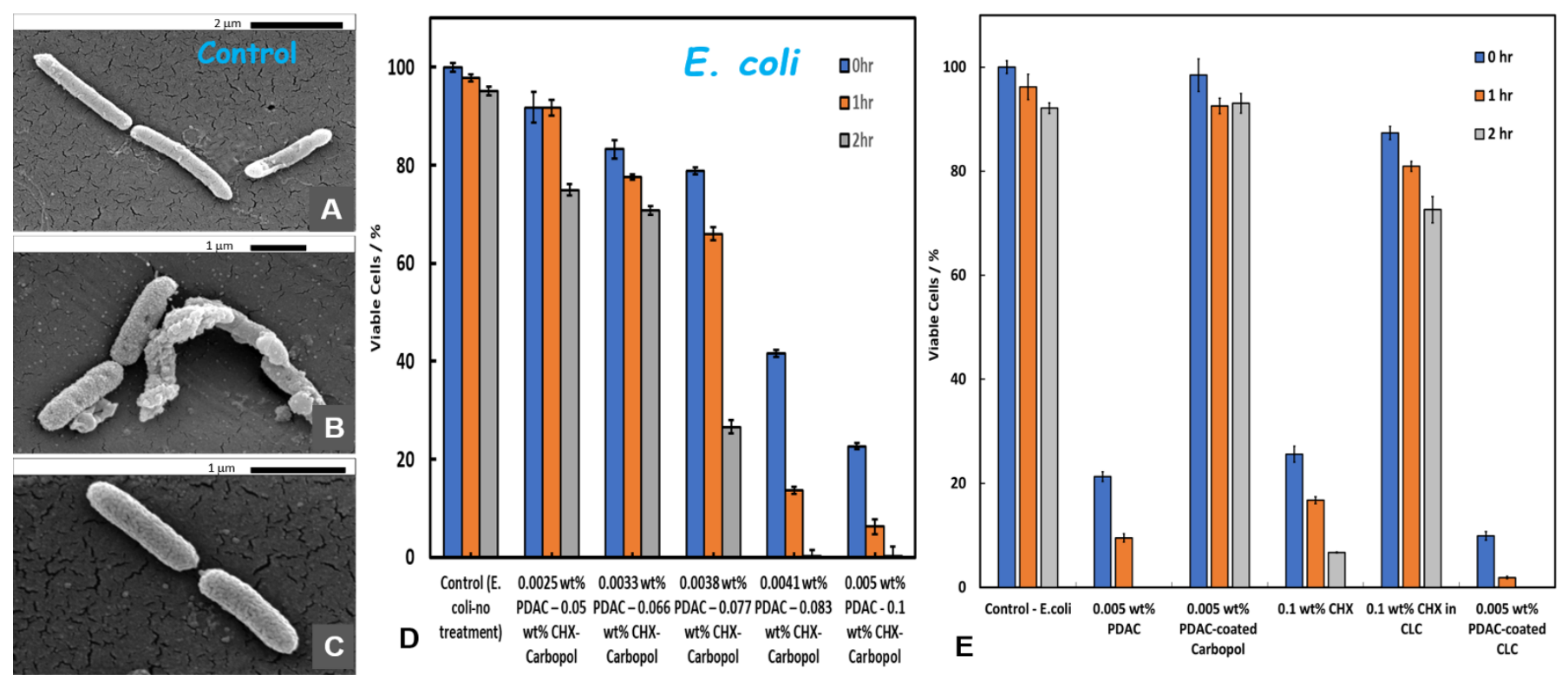

Figure 8. SEM images of $E$. coli cells after incubation in a suspension of PDAC-coated CLC for 2 hours at room temperature suspension. (A) The control sample of non-treated $E$. coli, (B) and (C) E. coli samples after treatment. (D) The viability of $E$. coli cells after timed exposure to antimicrobial formulations of PDAC-coated CLC at different concentrations for various time points (0, 1, 2 hours). The solutions were prepared by gradual dilution of a stock of 0.005 wt\% PDAC-coated 0.1 wt\% CHX loaded in 0.1 wt $\%$ Carbopol (CLC). (E) The viability of $E$. coli cells after exposure to various antimicrobial formulations in Milli-Q water for various time points ( $0,1,2$ hours). The graph compares the antibacterial activity of 0.005 wt \% PDAC, 0.005 wt\% PDAC coated Carbopol Aqua SF1 nanogel, 0.1 wt\% CHX, 0.1 wt\% CLC (without PDAC coating) and 0.005 wt\% PDAC-coated 0.1 wt\% CLC. The bacterial cell viability was tested with Promega CellTiter-Glo ${ }^{\circledR}$ assay.

This clustering and accumulation of particles is attributed to the attraction between the PDAC-functionalised nanogel particle and anionic surface of the cells. As a result, the local release of $\mathrm{CHX}$ from the nanocarrier directly onto the cell membrane appears to increase its anti-algal action. Figure 6D shows the concentration dependence of the PDAC-coated CLC on the microalgae cell viability. The cells were incubated in a series of suspension obtained by multiple dilution of a stock suspension of 0.005 wt\% PDAC-coated 0.1 wt\% CHX-loaded 0.1 wt\% Carbopol nanogel suspension. It can be seen that the $\mathrm{CHX}$ nanocarrier formulation containing a toxicity threshold concentration of 0.077 wt\% (or higher) of encapsulated $\mathrm{CHX}$ reduced the microalgae viability from $90 \%$ to $0 \%$ after 1 hour of incubation. The original stock suspension completely killed the microalgae even after 1 hour of incubation and was able to reduce the microalgae viability from $90 \%$ to less than $20 \%$ even upon instant treatment $(<5 \mathrm{~min}$ ).

We also compared the efficiency of the PDAC-coated CLC with the equivalent concentrations of free $\mathrm{CHX}$, non-coated $\mathrm{CLC}$ with the same concentration of $\mathrm{CHX}$ as well as the 0.005 wt\% PDACcoated nanocarrier without $\mathrm{CHX}$ and an equivalent concentration of free PDAC (0.005 wt\%). The microalgae cell viability for all these samples and controls after up to 2 hours of incubation are compared with the viability of the untreated cells in Figure 6E. One sees that although free PDAC on its own has significant toxicity against the microalgae, the PDAC-coated nanocarrier (without $\mathrm{CHX}$ ) does not show measurable toxicity when compared with the untreated control sample over the course of the experiment. Moreover, the results show that free $\mathrm{CHX}$ is more efficient in its anti-algal action comparted with equivalent amount of CLC. This can be explained by the fact that the CLC particles are negatively charged (Figure $2 E$ ) in the aqueous media and are electrostatically repelled from the negatively charged cell walls. However, the PDAC-coated CLC is not only more efficient than the non-coated CLC with the same amount of $\mathrm{CHX}$ but also it is also several times more effective than the treatment with the equivalent concentration of free $\mathrm{CHX}$. This occurs because of the electrostatic attraction between the cationic PDAC-coated CLC and the anionic cell membrane of the microalgae which allows the released $\mathrm{CHX}$ to disrupt locally the cell membrane causing the cell death.

\section{Anti-yeast activity of PDAC-coated CLC on S. cerevisiae}

We tested the action of PDAC-coated CLC towards yeast cells. Figure 7A compares the yeast cells viability upon incubation for up to 2 hours with PDAC-coated CLC with equivalent concentration of free $\mathrm{CHX}$, non-coated $\mathrm{CLC}$ with the same concentration of $\mathrm{CHX}$ as well as the $0.005 \mathrm{wt} \%$ PDAC-coated nanocarrier (without $\mathrm{CHX}$ ) and the equivalent concentration of free PDAC (at $0.005 \mathrm{wt} \%$ ). The results show that non-coated CLC is much less efficient than free $\mathrm{CHX}$ at the same concentration, which again is explained by the electrostatic repulsion between the yeast cell surface and negatively charged CLC particles, combined with the relatively slow release of $\mathrm{CHX}$ in the environment (cf. Figure3F). One can also see from this comparison that the yeast cells are completely unaffected by the PDAC-coated Carbopol nanocarrier (without CHX), although it has significant loss of viability in the presence of free PDAC at the same concentration. 


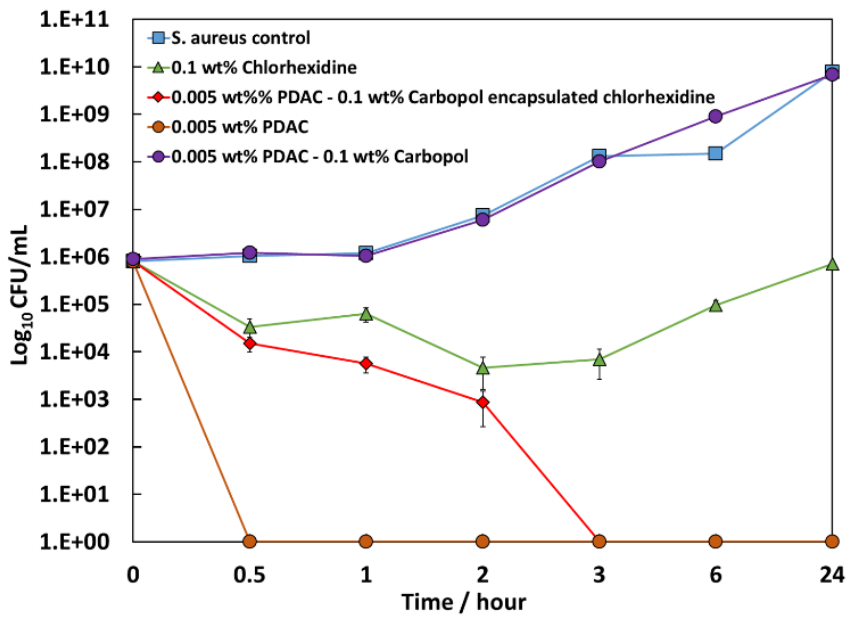

Figure 9. Time kill assay for chlorhexidine and $0.005 \mathrm{wt} \%$ PDAC-coated $0.1 \mathrm{wt} \% \mathrm{CHX}$ loaded in $0.1 \mathrm{wt} \%$ Carbopol (CLC), $0.005 \mathrm{wt} \%$ free PDAC and $0.005 \mathrm{wt} \%$ PDAC-coated $0.1 \%$ Carbopol (empty nanocarrier) tested against $S$. aureus. The results are presented as means $\pm S D(n=3)$. Some of the error bars are within the symbol size. The lines are guides to the eye.

PDAC is a very efficient antimicrobial agent as it is a cationic polymer which tends to disturb the cell walls even at very low concentrations. However, PDAC-coated CLC showed much higher anti-yeast efficiency that free $\mathrm{CHX}$ and $\mathrm{CLC}$ at the same equivalent $\mathrm{CHX}$ concentration. The explanation for this enhanced antimicrobial effect is related to the heterocoagulation of the positively charged PDAC-coated CLC on to the negatively charged cell walls which boosts the local $\mathrm{CHX}$ concentration directly on the yeast cells surface. Comparing Figure 6D with Figure 7A one can see that under the same condition the PDAC-coated CLC is more efficient against the microalgae than against yeast, which can be attributed to the much thicker cell wall of the yeast cells. In both cases of yeast and microalgae we observe a better antimicrobial action of the PDAC-coated CLC than free $\mathrm{CHX}$ and non-coated CLC. Figure $7 \mathrm{~B}$ shows the concentration dependence of the antiyeast action for a stock suspension of 0.005 wt\% PDAC-coated 0.1 wt\% CHX - loaded in $0.1 \%$ Carbopol. The yeast cell viability was measured after up to 2 hours of incubation in solutions obtained by multiple dilution of this stock suspension of PDACcoated CLC particles. The yeast cell viability can be seen to have reduced from $85 \%$ to less than $5 \%$ after 2 hours of incubation in the stock suspension, compared with $77 \%$ viability for the untreated yeast. The comparison of Figure 7B with Figure 6D also confirms that yeast is more resistant towards the PDACcoated CLC than the microalgae.

\section{Anti-bacterial action of PDAC-coated CLC on E. coli}

The antibacterial activity of PDAC-coated CLC with E.coli was investigated by incubation for up to 2 hours at room temperature with a fixed amount of E.coli cells removed from their culture media. Representative SEM images of the control sample of untreated E.coli are shown in Figure 8A, compared with $\mathrm{E}$. coli samples treated with PDAC-coated CLC (Figures 8B and $8 \mathrm{C}$ ). One can see that as with the microalgae (Figure $6 \mathrm{~B}$ and
$6 C)$, the E.coli cells have become densely coated with the PDACfunctionalised CLC nanoparticles after exposure to the nanocarrier suspension. The result of this accumulation of the $\mathrm{CHX}$-delivery vehicle on the cell viability was assessed in Figure $8 \mathrm{D}$ for various concentrations of the PDAC-coated CLC, obtained by gradual dilution of the stock of 0.005 wt\% PDAC-coated 0.1 wt\% CHX - loaded in 0.1\% Carbopol.

It should be noted that the threshold of toxicity of the PDACcoated CLC against E.coli is significantly lower than the one for yeast (cf. Figure 7B) but it is higher than for microalgae (cf. Figure $6 \mathrm{D}$ ). Figure $8 \mathrm{E}$ compares the E.coli cells viability upon incubation with PDAC-coated CLC and solutions with equivalent concentration of free $\mathrm{CHX}$, non-coated $\mathrm{CLC}$ with the same concentration of $\mathrm{CHX}, 0.005$ wt\% PDAC-coated "empty" Carbopol nanocarrier and free PDAC at the same concentration (0.005 wt\%). A very similar picture emerges from this comparison, as the equivalent results with microalgae (Figure $6 \mathrm{E}$ ) and yeast (Figure 7A). The PDAC-coated CLC shows much higher antibacterial efficiency against E.coli than both free $\mathrm{CHX}$ and non-coated $\mathrm{CLC}$ at the same equivalent concentration of $\mathrm{CHX}$. Again, the empty PDAC-coated nanocarrier is benign for E.coli, i.e. the coating alone does not contribute to any loss of E.coli cell viability.

\section{Antibacterial action of PDAC-coated CLC on S. aureus}

We determined the MIC and MBC of free $\mathrm{CHX}$ and PDAC-coated $\mathrm{CLC}$ on $S$. aureus as a common bacterial culture found in isolates from hospital acquired infected wounds. We found that at the same conditions the MIC of the PDAC-coated CLC is 2 times lower than this of free $\mathrm{CHX}$. The MBC of the PDAC-coated CLC is about 8 times lower than that of free $\mathrm{CHX}$ (see Table 2). These results illustrate the effect of the nano-encapsulation of the $\mathrm{CHX}$ into the Carbopol carrier and the targeted delivery of this antimicrobial agent directly on the surface for $S$. aureus, which requires several times lower overall $\mathrm{CHX}$ concentration to achieve the same effect as with free $\mathrm{CHX}$. The advantages of this enhancement of the $\mathrm{CHX}$ antibacterial action is several fold. This means that the same level of bacterial growth inhibition can achieved with 2 times lower $\mathrm{CHX}$ concentration and 8 lower minimal concentration of $\mathrm{CHX}$ encapsulated in $\mathrm{CLC}$ is needed for bactericidal action. Lowering the antimicrobial agent concentration is both cases can be beneficial from the point of view of economy of active material and lowering the overall side toxicity of the antibacterial formulation. This can be beneficial to reduce development of future bacterial resistance. Similar is the amplification effect of the PDAC-coated CLC on E. coli, C. reinhardtii, and S. cerevisiae compared with free $\mathrm{CHX}$ (Table 2). We also performed a comparative time kill assay on $S$. aureus using the same formulations of free $\mathrm{CHX}$ and PDAC-coated CLC at the same overall concentration of $\mathrm{CHX}$. The result is presented on Figure 9 along with the control of untreated bacteria. One sees that the PDAC-coated CLC has practically achieves $>5$ log reduction within 3 hours while the formulation based on free $\mathrm{CHX}$ has only time-limited effect on the growth of S. aureus. 
Table 2. Minimum inhibitory concentration (MIC) and minimum bactericidal/fungicidal concentration (MBC/MFC) of free CHX and PDAC-coated CLC against S. aureus, $E$. coli, C. reinhardtii, and S. cerevisiae. The lowest concentration of antimicrobial agent inhibiting/no growth was considered the MIC/MBC/MFC.

\begin{tabular}{|c|c|c|c|c|}
\hline & \multicolumn{2}{|c|}{$\mathrm{CHX}$} & \multicolumn{2}{|c|}{ PDAC-coated CLC } \\
\hline & MIC & $\mathrm{MBC}$ & MIC & $\mathrm{MBC}$ \\
\hline \multirow[t]{2}{*}{ S. aureus } & $2.5 \mu \mathrm{L} / \mathrm{mL}$ & $10 \mu \mathrm{L} / \mathrm{mL}$ & $1.25 \mu \mathrm{L} / \mathrm{mL}$ & $1.25 \mu \mathrm{L} / \mathrm{mL}$ \\
\hline & (0.05 wt\%) & (0.2 wt\%) & (0.025 wt\%) & (0.025 wt\%) \\
\hline \multirow[t]{2}{*}{ E. coli } & $5 \mu \mathrm{L} / \mathrm{mL}$ & $20 \mu \mathrm{L} / \mathrm{mL}$ & $2.5 \mu \mathrm{L} / \mathrm{mL}$ & $2.5 \mu \mathrm{L} / \mathrm{mL}$ \\
\hline & (0.1 wt\%) & (0.4 wt\%) & (0.05 wt\%) & (0.05 wt\%) \\
\hline \multirow[t]{2}{*}{ C. reinhardtii } & $5 \mu \mathrm{L} / \mathrm{mL}$ & $5 \mu \mathrm{L} / \mathrm{mL}$ & $0.625 \mu \mathrm{L} / \mathrm{mL}$ & $0.625 \mu \mathrm{L} / \mathrm{mL}$ \\
\hline & (0.1 wt\%) & (0.1 wt\%) & (0.0125 wt\%) & (0.0125 wt\%) \\
\hline \multirow[t]{2}{*}{ C. cerevisiae } & $5 \mu \mathrm{L} / \mathrm{mL}$ & $10 \mu \mathrm{L} / \mathrm{mL}$ & $1.25 \mu \mathrm{L} / \mathrm{mL}$ & $2.5 \mu \mathrm{L} / \mathrm{mL}$ \\
\hline & (0.1 wt\%) & (0.2 wt\%) & (0.025 wt\%) & (0.05 wt\%) \\
\hline
\end{tabular}

\section{Conclusions}

We have developed a novel surface functionalized nanocarrier for chlorhexidine based on lightly cross-linked acrylate copolymer nanogel particles (Carbopol Aqua SF1). This nanocarrier was surface-functionalised by coating with the cationic polyelectrolyte PDAC and showed a strong enhancement of the chlorhexidine antimicrobial action. We explored the effect of these $\mathrm{CHX}$-loaded nanocarrier on $\mathrm{C}$. reinhardtii microalgae, S. cerevisiae and E. coli for $\mathrm{CHX}$-loaded nanogel (CLC) with and without coating with the cationic polyelectrolyte (PDAC-coated CLC). We demonstrated that the cationic coating of the nanogel strongly amplifies the antimicrobial action of the loaded $\mathrm{CHX}$ against both $C$. reinhardtii, S. cerevisiae and $E$. coli even for short incubation times. The boost of the $\mathrm{CHX}$ antimicrobial activity was attributed to the favourable electrostatic attraction between the positively charged PDAC-coated CLC and the negatively charged cell membranes which leads to their attachment on the microbial cell walls where they release locally of highly concentrated $\mathrm{CHX}$ causing the cell death. SEM images of nanocarrier-treated cells showed the preferential deposition of the PDAC-coated CLC onto the cell membranes of all studied microbial cells. This type of very efficient cationic surfacefunctionalised nanogel carriers can be potentially applied to boost the antimicrobial action for a range of low-molecular weight cationic anti-fungal and anti-algal agents. Similar strategy could also find applications for enhancing the action of topical antibiotics and antifungal agents and may be used across different therapies to bypass antimicrobial resistance.

\section{Acknowledgements}

M.A. thanks the Iraqi Government, the Higher Committee for Education Development of Iraq and the Green University of Qasim, Babylon, Iraq for the financial support for his PhD study. P.J.W. is funded by a University of Hull Advanced Wound Care PhD cluster studentship.

\section{ORCID IDs}

Mohammed J. Al-Awady: 0000-0002-0506-6733
Paul J. Weldrick:

Matthew J. Hardman:

Gillian M. Greenway:

Vesselin N. Paunov:

0000-0002-1791-5659

0000-0002-6423-5074

$0000-0003-1873-8188$

0000-0001-6878-1681

\section{Notes and references}

1. K. S. Soppimath, T. M. Aminabhavi, A. R. Kulkarni and W. E. Rudzinski, J. Controlled Release, 2001, 70, 1-20.

2. P. S. Ayyaswamy, V. Muzykantov, D. M. Eckmann and R. Radhakrishnan, J. Nanotechn.in Eng. and Medicine, 2013, 4, 011001.

3. N. B. Graham and A. Cameron, Pure and Appl. Chem., 1998, 70, 12711275.

4. N. A. Peppas, Y. Huang, M. Torres-Lugo, J. H. Ward and J. Zhang, Ann. Review of Biomed. Eng., 2000, 2, 9-29.

5. D. Caccavo, S. Cascone, Sara; G. Lamberti, A. Barba, A. Anna Chem. Soc. Rev., 2018, 47, 2357-2373.

6. S. Liu, R. Maheshwari and K. L. Kiick, Macromolecules, 2009, 42, 3-13.

7. W. Shen, Y. Chang, G. Liu, H. Wang, A. Cao and Z. An, Macromolecules, 2011, 44, 2524-2530.

8. H. Urakami, J. Hentschel, K. Seetho, H. Zeng, K. Chawla and Z. Guan, Biomacromolecules, 2013, 14, 3682-3688.

9. D. Foulkes, J. Periodontal Res., 1973, 8, 55-60.

10. G. Greenstein, C. Berman and R. Jaffin, J. Periodontology, 1986, 57, 370377.

11. M. P. Young, D. H. Carter, H. V. Worthington, J. F. McCord, M. Korachi and D. B. Drucker, Clinical Oral Implants Res., 2002, 13, 20-29.

12. C. Estrela, R. G. Ribeiro, C. R. Estrela, J. D. Pécora and M. D. Sousa-Neto, Brazilian Dental J., 2003, 14, 58-62.

13. J. F. Siqueira, I. N. Rôças, S. S. Paiva, T. Guimarães-Pinto, K. M. Magalhães and K. C. Lima, Oral Surgery, Oral Medicine, Oral Pathology, Oral Radiology and Endodontology, 2007, 104, 122-130.

14. M. Bral and C. Brownstein, Dental Clinics of North America, 1988, 32, 217241.

15. N. Lang and M. C. Brecx, J. Periodontal Res., 1986, 21, 74-89.

16. H. Löe and C. Rindom Schiøtt, J. Periodontal Res., 1970, 5, 79-83.

17. N. Lavoine, N. Tabary, I. Desloges, B. Martel and J. Bras, Colloids and Surfaces B: Biointerfaces, 2014, 121, 196-205.

18. C. J. Seneviratne, K. C.-F. Leung, C.-H. Wong, S.-F. Lee, X. Li, P. C. Leung, C. B. San Lau, E. Wat and L. Jin, PloS One, 2014, 9, e103234.1-7.

19. H.C. Stuart, S.A. Schwartz, T.J. Beeson, C.B. Owatz, J. endodontics, 2006 , 32, 93-98.

20. I. C. Yue, J. Poff, M. a. E. Cortés, R. D. Sinisterra, C. B. Faris, P. Hildgen, R. Langer and V. P. Shastri, Biomaterials, 2004, 25, 3743-3750.

21. B. Jiang, G. Zhang and E. M. Brey, Acta biomaterialia, 2013, 9, 4976-4984.

22. H. Lboutounne, J.-F. Chaulet, C. Ploton, F. Falson and F. Pirot, J. Controlled Release, 2002, 82, 319-334.

23. M. E. Barbour, S. E. Maddocks, N. J. Wood and A. M. Collins, Internat. J. Nanomedicine, 2013, 8, 3507-3519.

24. A.F. Halbus, T.S. Horozov, V.N. Paunov, Adv. Colloid Interf. Sci., 2017, 249, 134-148. 
25. A.A.K. Das and V.N. Paunov, Microbiologist, June 2014, pp.16-19. https://issuu.com/societyforappliedmicrobiology/docs/2014_06_micro biologist

26. M.J. Al-Awady, G.M. Greenway, V.N. Paunov, RSC Adv., 2015, 5, 3704437059.

27. M.J. Al-Awady, A. Fauchet, G.M. Greenway, V.N. Paunov, J. Mater. Chem. B, 2017, 5, 7885-7897.

28. C. Frangville, M. Rutkevicius, A.P. Richter, O.D. Velev, S.D. Stoyanov, V.N. Paunov, ChemPhysChem, 2012, 13, 4235-4243.

29. A.P. Richter, J.S. Brown, B. Bharti, A. Wang, S. Gangwal, K. Houck, E.A. Cohen Hubal, V.N. Paunov, S.D. Stoyanov, O.D. Velev, Nat. Nanotechnol., 2015, 10, 817-823.

30. A.P. Richter, B. Bharti, H.B. Armstrong, J.S. Brown, D. Plemmons, V.N. Paunov, S.D. Stoyanov, O.D. Velev, Langmuir 2016, 32, 6468-647.

31. C. A. Lubrizol, Noveon Consumer Specialties, Technical Data Sheet, 2007, 294.

32. D. S. Gorman and R. Levine, Proc. Natl. Acad. Sci. U. S. A., 1965, 54, 16651669.

33. S. Hutner, L. Provasoli, A. Schatz and C. Haskins, Proc. Am. Philos. Soc., 1950, 94, 152-170.

34. S. Sahoo, C. K. Chakraborti and S. C. Mishra, J. Adv. Pharm. Techn. \& Res., 2011, 2, 195-204.

35. M. Moharram and M. Khafagi, J. Appl. Polym. Sci., 2007, 105, 1888-1893.

36. A. Kovtun, D. Kozlova, K. Ganesan, C. Biewald, N. Seipold, P. Gaengler, W. H. Arnold and M. Epple, RSC Advances, 2012, 2, 870-875.

37. K. Garala, P. Joshi, M. Shah, A. Ramkishan and J. Patel, Internat. J. Pharm. Investig., 2013, 3, 29-41.

38. P. Larkin, Infrared and Raman spectroscopy; principles and spectral interpretation, Elsevier, 2011.

39. A. Muñoz-Bonilla, M. Fernández-García, Eur. Polymer J., 2015, 65, 46-62.

40. A. Muñoz-Bonilla, M. Fernández-García, Prog. Polymer Sci., 2012, 37, 281 339. 